ORIGINAL ARTICLE

\title{
Sociodemographic Correlates of HIV Discordant and Concordant Couples in Anambra State, Nigeria
}

\author{
Chinomnso Nnebue ${ }^{1,2 *}$, Adaeze Anaekwe ${ }^{2}$, Chidebe Anaekwe ${ }^{2}$
}

OPEN ACCESS

Citation; Chinomnso Nnebue, Adaeze Anaekwe, Chidebe Anaekwe

Sociodemographic Correlates of HIV Discordant and Concordant Couples in Anambra State, Nigeria. J Health Sci 2017;27(4):363. doi:

http://dx.doi.org/10.4314/ejhs.v27i4.7

Received: February 4, 2017

Accepted: February 8, 2017

Published: July 1, 2017

Copyright: () 2017 Nnebue, C., et al. This is an open access article distributed under the terms of the Creative Commons Attribution License, which permits unrestricted use, distribution, and reproduction in any medium, provided the original author and source are credited.

Funding: None.

Competing Interests: The authors

declare that this manuscript was approved

by all authors in its form and that no

competing interest exists.

Affiliation and Correspondence:

${ }^{1}$ HIV Care, Nnamdi Azikiwe

University Teaching Hospital,

Nnewi, Nigeria

${ }^{2}$ Community Medicine, Nnamdi

Azikiwe University Teaching

Hospital, Nnewi, Nigeria

"Email: nnebnons@yahoo.com

\section{ABSTRACT}

BACKGROUND: The contribution of discordant partnerships to the burden of HIV/AIDS is significant. An understanding of the characteristics of HIV-affected couples will help modify preventive strategies. The aim of this study was to compare the HIV discordant and concordant partnerships for sociodemographic determinants in comprehensive health centers in Anambra State, Nigeria.

METHODS: This was an institution based case-control study of 289 (148 HIV-concordant and $141 \mathrm{HIV}$-discordant) couples, selected using multistage sampling technique. Data collection was done through nterview using semi-structured questionnaire, while analysis was performed with Statistical Package for Social Sciences version 22.0. Chi-square and t tests were used to identify statistically significant associations between variables. Significance level was set at $p$ value of $\leq 0.05$.

RESULTS:There were more HIV-discordant positive males $83(28.6 \%)$ than females $58(20.1 \%)(p=0.043)$. The mean age $(S D)$ of respondents was 37.8(9.8) years. Concordant couples tended to be younger than discordant couples, with differences in mean ages of 2.41 years $(p=0.028)$ for males and 2.87 years $(p=0.007)$ for females. There were no significant differences in proportion of remarriages $(p=0.625)$ and type of marriage $(p=0.900)$. The majority of remarriages among discordant couples 15(65.2\%), were due to divorce of previous spouses $(p=0.054)$.

CONCLUSIONS: This study found that there were more HIV positive males than females among discordant couples; females in discordant relationships were generally younger than their concordant counterparts. Concordant couples tended to be younger than discordant couples. Such knowledge should be factored in designing novel couple-targeted preventive strategies.

KEYWORDS: Sero-concordant, couples, sero-discordant, HIV, determinants, Nigeria

DOI: http://dx.doi.org/10.4314/ejhs.v27i4.7 


\section{INTRODUCTION}

Couples are said to be human immunodeficiency virus (HIV)-affected when either one or both partners are infected with HIV (1). Partners are categorized as HIV-concordant when both partners are HIV infected. HIV discordance refers to a situation where one of the partners is HIV positive while the other is HIV negative (1). Hard discordance refers to a situation where the male is the positive partner while soft discordance is a situation where the female is the positive partner (2).

Studies have reported a high prevalence of HIV serodiscordance among heterosexual couples in Africa $(3,4,5)$. Serodiscordant partnerships account for nearly $18-31 \%$ of couples in high HIV prevalence countries $(6,7)$. Nigeria contributes substantially to the global burden of HIV/Acquired Immune Deficiency Syndrome (AIDS) with nearly 3.3 million people living with HIV/AIDS (PLWHA) in 2013. This makes it the country with the second highest number of PLWHA globally (8).

Despite this, with the exception of participants tested in a research context, many individuals living in resource limited climes, including Nigeria, are unaware of their own and their partners own HIV statuses (9). Nonetheless, previous studies revealed that HIV discordant partnerships constitute a core at risk group for the transmission of HIV $(10,11)$. Gray et al. reported that HIV-negative members of discordant partnerships are at extremely high risk of infection, with the annual incidence 10 to 100 fold higher than that of their HIV concordant negative counterparts (11).

Preventing new HIV infections through identification of groups at high risk, supplemented by provision of care and support for infected people, has been a widely accepted intervention approach in fighting HIV and AIDS $(12,13)$. This population thus constitutes the target group for HIV prevention strategies even as the mechanisms that underlie HIV serodiscordance are poorly understood. Untill recently, however, the long list of HIV risky groups missed serodiscordant couples (14).
Anambra State has the highest prevalence of HIV/AIDS in South-Eastern Nigeria (15) and by extrapolation a high rate of discordance. This study has become timely, especially in this era of health sector reform. It is expected that the findings of our would help to address the knowledge gaps presently existent in the area of HIV discordance, guide recommendations and serve as a basis for policy formulation on appropriate interventions towards the management of this special group. This study was undertaken to compare the sociodemographic correlates of HIVinfected individuals in concordant and discordant partnerships in comprehensive health centers in Anambra State, Nigeria.

\section{MATERIALS AND METHODS}

Study area, period and design: This institution based case-control study was conducted from January to April 2013 at Ukpo in Dunukofia local government area and Neni in Anaocha local government area of Anambra, Nigeria (16).The study sites were the comprehensive health centers (CHC) in Ukpo and Neni. Ukpo hosts a 30-bed facility which employs various cadre of health workers. At the time of this study, the first facility had 482 PLWHA accessing care, ran a HIV clinic twice a week and had an average weekly attendance of 60 patients per clinic. One hundred and twenty of the couples were in discordant relationships, 140 couples were concordant, while 70 people were single adults and 12 were below 18 years. The second facility (Neni) operates a linkage system with the first $\mathrm{CHC}$, as both facilities were manned by the same group of doctors on a rotational basis. The center presently had 700 PLWHA accessing care, ran HIV clinic twice weekly and an average weekly attendance of 100 patients. One hundred and eighty of the couples were in discordant relationships, 180 couples were concordant, with 120 adult singles and 40 teenagers.

Study population and sampling technique: The reference population comprised the HIVdiscordant and concordant couples in Dunukofia and Anaocha local government areas of Anambra state, while the target population consisted of the

DOI: http://dx.doi.org/10.4314/ejhs.v27i4.7 
HIV discordant and concordant couples accessing care at the CHCs in Ukpo and Neni Anambra State. Sero-discordant/ concordant couples who had been in sexual relationship for at least six months prior to the study, had disclosed their HIV statuses to the each other and both partners aged 18 years or older, met the inclusion criteria. Those in sero-discordant / concordant relationships for more than six months who did not give their consent were excluded

Minimum sample size was calculated using formula for comparison of 2 proportions [HIV discordant and concordant partnerships for sociodemographic determinants] (17). Proportion of discordant couples $=50 \%$ since there is no documented literature comparing HIV discordant and concordant partnerships for sociodemographic determinants, were considered to determine the final sample size at 131. Anticipating a response rate of $90 \%,(\mathrm{f}=\%$ of response $=90 \%(0.9))$ to compensate for non-response, the study sample size was calculated as $\mathrm{n} / \mathrm{f}(18)=131 / 0.9=145$ couples per group.

Multistage sampling technique was used to conduct this study. Firstly, from the four comprehensive health centers in Anambra State, two were chosen by simple random sampling using balloting i.e. comprehensive health centers Ukpo and Neni. Secondly, from the clinics, the sampling frames of the discordant and concordant couples accessing care were obtained. This consisted of the lists of these couples accessing care at these clinics. At the time of the study, the total number of discordant couples at the two comprehensive centers was 300 while the number of concordant couples was 320 . For the discordant couples, simple random sampling using a table of random numbers was employed to select the 145 couples from the sampling frame. Same was done to obtain the sample size from the concordant couples sampling frame.

Data collection and analysis: Pre-tested, interviewer-administered semi-structured questionnaire was used to collect data. The questionnaire for this study was adapted from that used by the Human Sciences Research Council of South Africa and the Global Network of people living with HIV/AIDS (19). The questionnaire generated data on the sociodemographic characteristics of the respondents. All those who gave consent and whose appointments fell within the study period were interviewed while those whose appointments fell outside the study periodhad their interviews fixed with them at a convenient time and place.

To ensure data quality, training of data collection and field monitoring of data collection were done. The data collection team met at the end of every day to share experiences, submit completed forms and solve field problems encountered.At the end of the study, one of the questionnaires could not be traced during analysis; hence only 289 questionnaires were analyzed. The data were reviewed and entered into the computer. Data were cleaned by carrying out range as well as by consistency checks. Frequencies of the variables were assessed using univariate analysis, while bivariate analysis, using chi-square and $\mathrm{t}$ tests, were employed in testing associations between several variables, comparing concordant and discordant couples. Level of significance was set at 5\% or less. Descriptive and analytical statistics of the data were carried out using Statistical Package for Social Sciences (SPSS) Windows version 22.0 (20). Descriptive data were presented as charts, simple frequencies and percentages.

Ethical consideration: A written informed consent was obtained from each participant for the conduct and publication of this research study and assurance of confidentiality was given. Study participants were free to refuse or withdraw from the study at any time without any penalty. The purpose and objectives of the study were explained to each participant prior to the interview. All authors hereby declare that the study has been examined and approved by the Nnamdi Azikiwe University Teaching Hospital Ethics Committee Nnewi, Nigeria, and has therefore been performed in accordance with the ethical standards laid down in the 1964 Declaration of Helsinki. 


\section{RESULTS}

Table 1 shows the sociodemographic characteristics of respondents. Data were obtained from 289 respondents, consisting of 148 HIVconcordant, and $141 \mathrm{HIV}$-discordant couples. The mean age (SD) of all respondents was 37.8(9.8). The age group of 36-40 years was the commonest male age group for HIV discordant and HIV concordant couples. While 25-30 years was the commonest female age group for both discordant and concordant couples. There were more HIVpositive males than females among discordant couples $(p=0.043)$. Most of the male 201(69.6\%) and female $216(74.7 \%)$ respondents had at least

Table 1: Sociodemographic characteristics of HIV discordant and concordant couple in comprehensive health centers in Anambra state, Nigeria from January and April 2013(N=578)

\begin{tabular}{|c|c|c|c|c|c|c|}
\hline & & \multicolumn{2}{|c|}{ Concordant Couples } & \multicolumn{2}{|c|}{ Discordant Couples } & \multirow[b]{2}{*}{$\begin{array}{c}\text { Group Total } \\
\text { n }(\mathbf{1 0 0 \% )} \\
\end{array}$} \\
\hline Characteris & tics & $\begin{array}{r}\text { male } \\
\text { concordant } \\
\mathrm{n}(\%) \\
\end{array}$ & $\begin{array}{r}\text { female } \\
\text { concordant } \\
\mathrm{n}(\%) \\
\end{array}$ & $\begin{array}{r}\text { male } \\
\text { discordant } \\
\mathbf{n}(\%) \\
\end{array}$ & $\begin{array}{r}\text { female } \\
\text { discordant } \\
n(\%) \\
\end{array}$ & \\
\hline \multirow{7}{*}{ 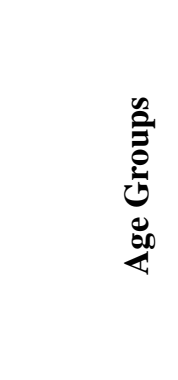 } & $18-24$ & $0(0.0)$ & $18(85.7)$ & $0(0.0)$ & $3(14.3)$ & $21(100)$ \\
\hline & $25-29$ & $21(13.4)$ & $59(37.6)$ & $17(10.8)$ & $60(38.2)$ & $157(100)$ \\
\hline & $30-34$ & $36(35.6)$ & $28(27.7)$ & $20(19.9)$ & $17(16.8)$ & $101(100)$ \\
\hline & $35-39$ & $36(29.8)$ & $14(11.6)$ & $43(35.5)$ & $28(23.1)$ & $121(100)$ \\
\hline & $40-44$ & $18(34.6)$ & $10(19.2)$ & $16(30.8)$ & $8(15.4)$ & $52(100)$ \\
\hline & $45-49$ & $18(25.4)$ & $15(21.1)$ & $23(32.4)$ & $15(21.1)$ & $71(100)$ \\
\hline & $\begin{array}{l}50-54 \\
\geq 55\end{array}$ & $\begin{array}{r}12(48.0) \\
7(48.3)\end{array}$ & $\begin{array}{r}2(8.0) \\
2(10.5)\end{array}$ & $\begin{array}{r}8(32) \\
13(47.4)\end{array}$ & $\begin{array}{r}3(12) \\
7(21.0)\end{array}$ & $\begin{array}{l}25(100) \\
30(100)\end{array}$ \\
\hline \multirow{4}{*}{ } & Nil & $1(20.0)$ & $0(0.0)$ & $3(60.0)$ & $1(20.0)$ & $5(100)$ \\
\hline & Primary & $50(32.0)$ & $36(23.1)$ & $34(21.8)$ & $36(23.1)$ & $156(100)$ \\
\hline & Secondary & $58(21.4)$ & 83 (30.6) & $56(20.7)$ & $74(27.3)$ & $271(100)$ \\
\hline & Tertiary & $39(26.7)$ & $29(19.9)$ & 48 (32.9) & $30(20.5)$ & $146(100)$ \\
\hline \multirow{5}{*}{ } & Farmer & $12(38.7)$ & $4(12.9)$ & $10(32.3)$ & $5(16.1)$ & $31(100)$ \\
\hline & Civil Serv. & $97(28.2)$ & $81(23.6)$ & $82(23.8)$ & $84(24.4)$ & $344(100)$ \\
\hline & Trader & $28(24.5)$ & $30(26.3)$ & $32(28.1)$ & $24(21.1)$ & $114(100)$ \\
\hline & Others & $11(15.7)$ & $18(25.7)$ & $16(22.9)$ & $25(35.7)$ & $70(100)$ \\
\hline & Unemployed & $0(0.0)$ & $14(77.8)$ & $1(5.5)$ & $3(16.7)$ & $18(100)$ \\
\hline \multirow{3}{*}{ 旁 } & Monogamy & $132(50.3)$ & & $130(49.6)$ & & $262(100)$ \\
\hline & Polygamy & $15(55.6)$ & & $12(44.4)$ & & $27(100)$ \\
\hline & Polyandry & $6(50.0)$ & & $6(50.0)$ & & $12(100)$ \\
\hline \multirow{7}{*}{ 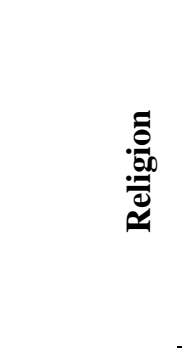 } & Pentecostal & $34(47.8)$ & & $37(52.2)$ & & $71(100)$ \\
\hline & Anglican & $39(49.4)$ & & $40(50.6)$ & & $79(100)$ \\
\hline & Rom. Cath. & $56(53.8)$ & & $48(46.2)$ & & 104(100) \\
\hline & Jeh. Wit & $3(60.0)$ & & $2(40.0)$ & & $5(100)$ \\
\hline & Sabbath & $9(52.9)$ & & $8(47.1)$ & & $17(100)$ \\
\hline & Moslem & $0(0.0)$ & & $1(100)$ & & $1(100)$ \\
\hline & Trad. & $7(63.6)$ & & $4(36.4)$ & & $11(100)$ \\
\hline
\end{tabular}

DOI: http://dx.doi.org/10.4314/ejhs.v27i4.7 
secondary school education, with no significant difference in level of education between concordant and discordant couples. Roman Catholicism was the predominant religion 104(36.0\%), closely followed by Anglican $80(27.7 \%)$, though there was no significant difference in religion between concordant and discordant couples.

Figure 1 is a bar chart showing age group of male and female partners in concordant and discordant relationships. Female respondents in discordant relationships were generally younger, with more of them <36 years old, compared to those in concordant relationships. Concordant couples tended to be younger than discordant couples, with difference in mean ages of (2.41 years; $\mathrm{t}=-2.214, \mathrm{p}=0.028)$ for males and (2.87 years; $\mathrm{t}=-2.714, \mathrm{p}=0.007$ ) for females, respectively.

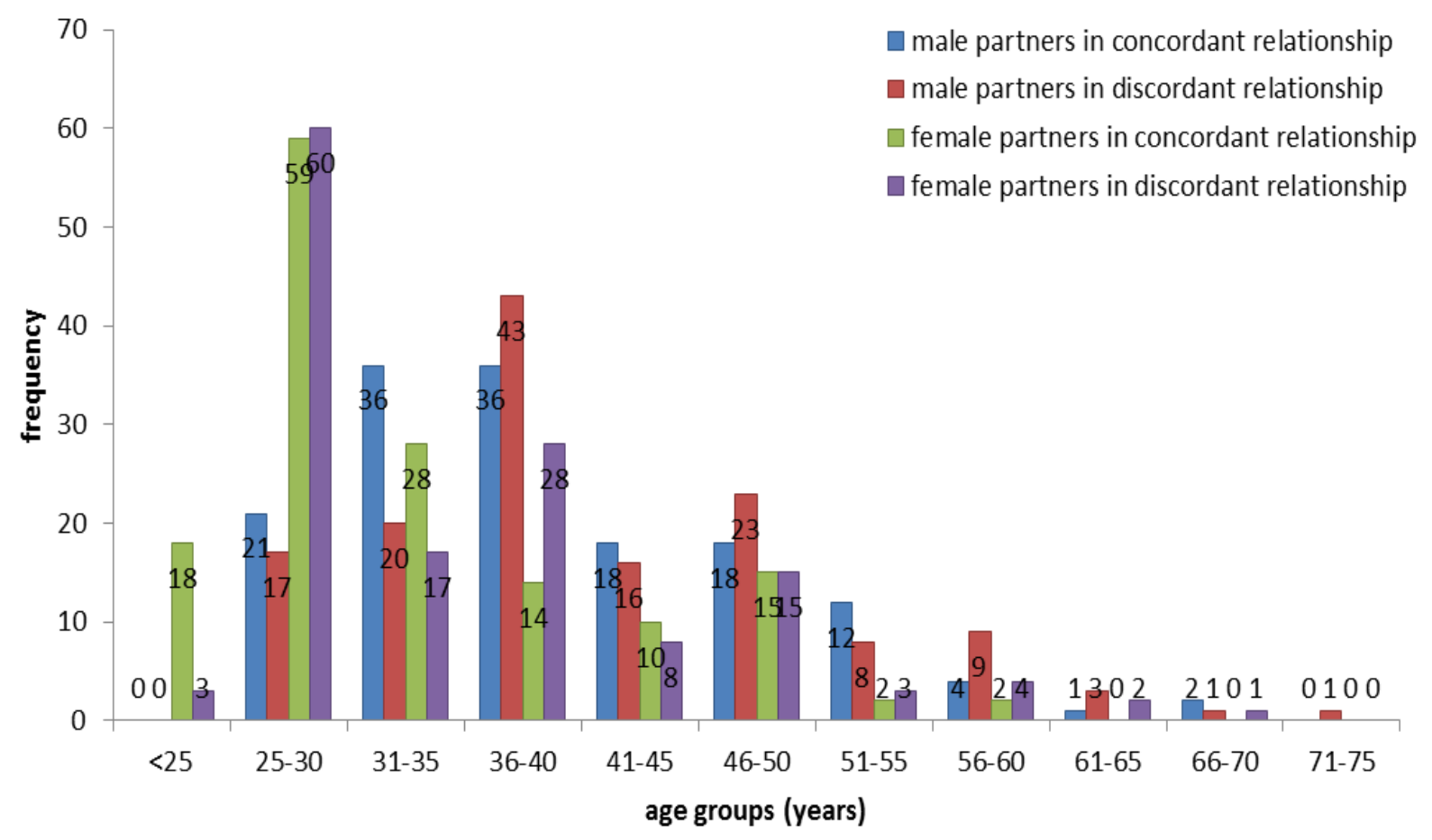

Figure 1: Bar chart showing age group of male and female partners in HIV concordant and discordant relationships in comprehensive health centers in Anambra State, Nigeria from January and April 2013

Table 2 highlights types of marriage, remarriage and divorce rate among concordant and discordant couples Monogamy was the commonest type of marriage union, 262(90.65\%), for both concordant and discordant couples $(\chi 2=0.212$, df $=2, \mathrm{p}=$ $0.900)$. Death of previous spouse, $31(57.4 \%)$, and divorce, 23(42.6\%), were the common reasons for remarriage. There was no significant difference in the proportion of remarried partners, comparing concordant and discordant couples $(\chi 2=0.24, \mathrm{df}=$ $1, \mathrm{p}=0.625)$. However, more of the concordant couples that had remarried did so due to death of their previous spouses, 19(61.3\%), while more of the discordant couples that had remarried did so due to divorce of previous spouses, 15(65.2\%), $(\chi 2=3.7, p=0.054)$.

DOI: http://dx.doi.org/10.4314/ejhs.v27i4.7 
Table 2: Marriage, Remarriage and Divorce Rate among of HIV discordant and concordant couplesin comprehensive health centers in Anambra state, Nigeria from January and April 2013

\begin{tabular}{lccc}
\hline Characteristics & Concordant & Discordant & p value \\
\cline { 2 - 3 } & $\mathbf{N}(\%)$ & $\mathbf{N}(\%)$ & \\
\hline Type of marriage & $15(5.2)$ & $12(4.1)$ & 0.900 \\
$\quad$ Polygamy & $132(45.67)$ & $130(444.98)$ & \\
Monogamy & $6(2.1)$ & $6(6.1)$ & \\
$\quad \begin{array}{l}\text { Polyandry } \\
\text { One of the couples }\end{array}$ & & & \\
previously married & $25(8.7)$ & $21(7.4)$ & 0.625 \\
$\quad$ Yes & $122(42.4)$ & $120(41.7)$ & \\
No & $19(35.2)$ & $12(22.2)$ & \\
Reason for remarriage & $8(14.8)$ & $14(27.8)$ & 0.054 \\
$\quad$ Death of spouse & &
\end{tabular}

Figure 2 is a bar chart showing occupation of HIV couples. Most of the respondents had occupations, with the civil service accounting for over half of the occupations in male and female partners (61.7 and $57.1 \%$ respectively), and about two-thirds of the couples $(67.9 \%)$ had same type of occupation.

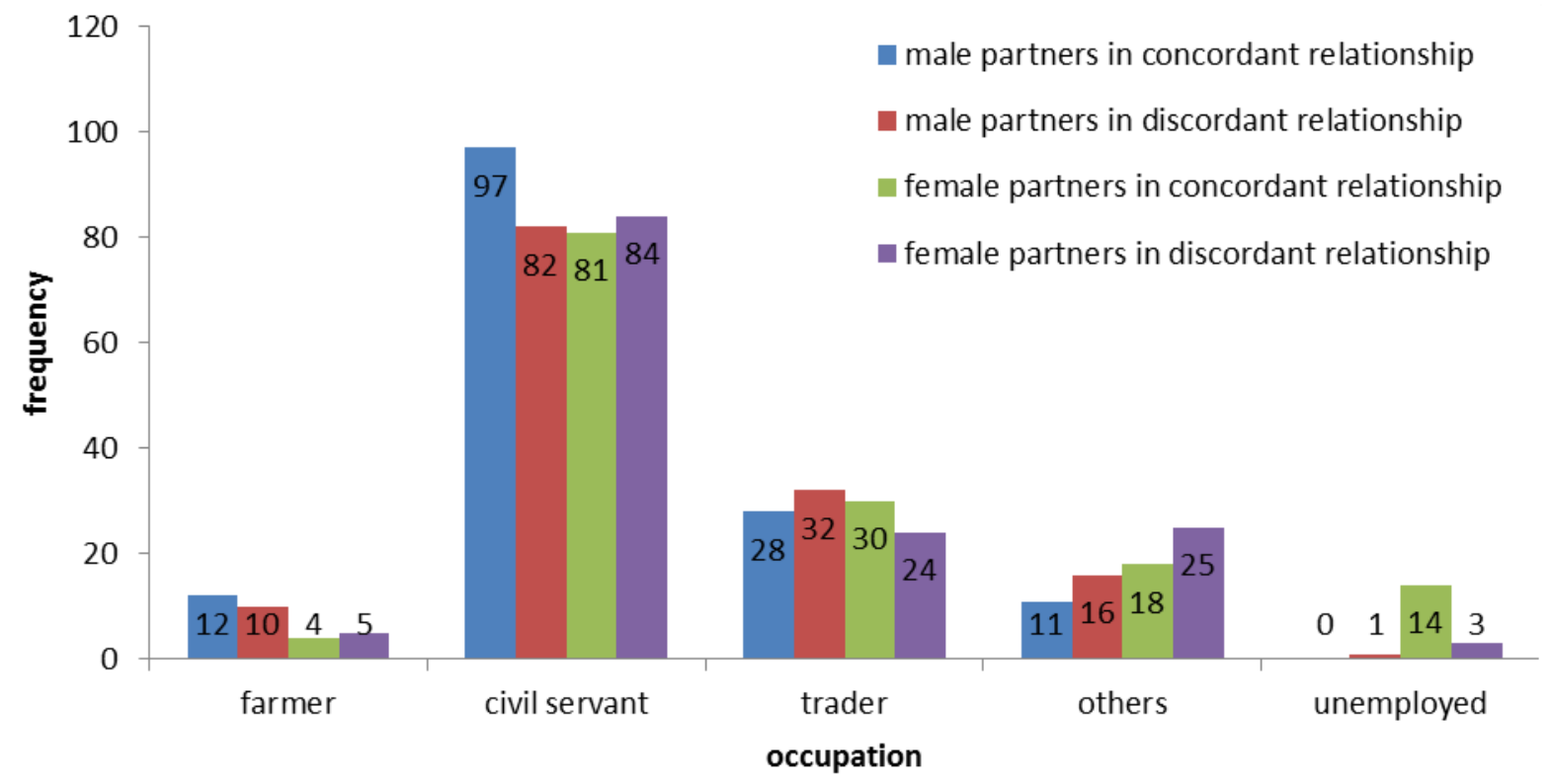

Figure 2: Bar chart showing occupation of HIV discordant and concordant couplesin comprehensive health centers in Anambra state, Nigeria from January and April 2013

\section{DISCUSSION}

DOI: http://dx.doi.org/10.4314/ejhs.v27i4.7 
This case-control study assessed the sociodemographic correlates of HIV discordant and concordant couples presenting in comprehensive health centers in Anambra State, Nigeria. A high response rate (99.2\%) was obtained from this study which is consistent with the rates obtained in studies by Kaiser et al., (7) in Kenya, Ngilangwa et al., (21) in Tanzania, Nozaki et al., (22) in Zambia and Tadesse in Ethiopia (23)

The findings of the index study revealed that female respondents that were in discordant relationships were generally younger, with more of them being less than 36 years old, compared to female respondents in concordant relationships. This finding agrees with reports that HIV serodiscordant relationship was associated with age (35-45 years) for women, and that women with older men partners were reported as less likely to be in HIV serodiscordant relationships (21). Our study also revealed that concordant couples tended to be younger than discordant couples. This is in tandem with the findings of a study by Hugonnet et al., which showed that both males and females in concordant positive relationships were significantly younger than those in discordant relationships (24).

From our findings, there were more HIVdiscordant positive males than females among the discordant couples. This finding is consistent with findings in Indian studies, which observed that males were the index partners in the majority of HIV-discordant partnerships $(1,25)$.This is in contrast with the findings by Walque in which more of the population assessed were discordant females (11)in a Tanzaniaand in study which reported that in serodiscordant unions, women were likely to be HIV positive than men $(71 \%$ versus $29 \%$ respectively $\mathrm{p}<0.001$ ) (21).The variations may be due to differences in methodologies such as study areas, study designs, subject characteristics and sampling methods. The findings of our study were however supported by evidences from studies which suggest that men are more likely to introduce HIV infection into sexually stable partnerships, probably due to early sexual debut, concurrent partnerships and sociocultural practices that encourage men to engage in extra marital relationships $(8,14,26,27,28)$. This makes it essential to devise male-centered counselling and prevention strategies.

Our findings revealed that monogamy was the commonest type of marriage $(90.65 \%)$, with no significant difference in the type of marriage, comparing concordant and discordant couples. However, HIV discordance has been linked with having of two or more sexual partners $(\mathrm{AOR}=4.06)(23)$ as well as increasing number of lifetime sexual partners in women (AOR 1.5, p <0.0001) (28) than HIV concordance. HIV prevention messages have focused on risk in the context of casual relationships outside of marriage (29). This creates a scenario that depicts marriage as a safe haven, usually without emphasizing the type of marriage nor the importance of HIV testing before marriage or within already long time married couples who have not been previously tested. (30).

From the index study, death of previous spouse $(57.4 \%)$ and divorce $(42.6 \%)$ were the common reasons for remarriage. However, more of the concordant couples that had remarried did so due to death of their previous spouses $(61.3 \%)$, while more of the discordant couples that had remarried did so due to divorce of previous spouses $(65.2 \%)$. This concurs with the results of a cross-sectional interview of 102 HIV positive pregnant women in concordant and discordant relationships in Thailand, which found higher previous divorce rates among women in discordant relationship (31).

The authors observed a non-statistically significant association between HIV sero concordance cum discordance and educational level. Though we could not cite study findings in keeping with this or otherwise, higher educational status has been noted as a key sociodemographic factor that positively affects psychosocial adjustment among PLWHA (29). Further studies are needed in this area.

From our study, most of the respondents had occupations, with the civil service accounting for over half of the occupations in male and female partners (about six in every ten respectively). Previous studies have observed similar 
socioeconomic differences, and discordant couples are more likely to be employed and to have higher incomes $(1,32)$. Employment has been described as a key indicator of an individual's socioeconomic status and thus a surrogate of a couple's willingness to adopt protective behavior once a partner's reactive HIV status is known (28). This corroborates the findings of other studies conducted in Africa and China. These studies reported that individuals who were uninfected, but exposed to HIV-infected partners from HIV-1-discordant heterosexual couples demonstrated greater indicators of poverty.such as a poor education and insufficient income and, consequently, reported a low adherence to condom use and a large number of children $(21,33,34,35)$. Further studies are needed in this area, too.

We observed no significant difference in religion between concordant and discordant couples. However, findings elsewhere reported a link to religious practices, which could influence sexual behavior (36). Although we did not elicit information on the duration the individuals had practiced their religious precepts or ascertain whether they ascribed to them after the disclosure of their partner's HIV status; this observed variation may be due to differences in methodologies such as study areas, subjects' characteristics, sampling procedures and data collection techniques.

While our study maintained its internal validity through use of standardized HIV tests and pre-tested questionnaire, its findings should be cautiously generalized because of the sampling of two out of four health centers. Also, we relied on self-reporting of couples on sociodemographic and other data. Self-reporting is prone to bias which can lead to underreporting or overreporting of one's information. Temporal bias could have happened, as in the case of relation between discordance and reason for remarriage. Lastly, we were not able to enquire more information on other factors such as income, partner's age, educational status and occupation that could have been associated with HIV serodiscordance.

In conclusions, in this study, there were more HIV positive males than females among discordant couples. Female respondents that were in discordant relationships were generally younger, compared to their concordant counterparts. Concordant couples tended to be younger than discordant couples. The respective commonest reason for remarriages was death of their previous spouses among concordant couples and divorce of previous spouses among discordant couples

Based on the findings in this study, we recommended as follows: There is need for early integrated couple HIV counselling and testing (more rigorous among males). Partners should be encouraged to disclose their HIV status to each other. There should be early adoption of safe sexual practices by discordant couples to reduce the proportion of such couples transforming into concordant partnerships. SInce female respondents in discordant relationships were generally younger, we strongly suggest use of multiple channels of communication in promoting campaigns that increase utilization of couple HIV counselling and testing services among this age group

\section{REFERENCES}

1. Mehra B, Bhalla P, Rawat D, Kishore J. A study of HIV-concordant and -discordant couples attending voluntary counselling and testing services at a tertiary care center in North India. Indian $J$ Public Health 2015;59:306-9.

2. Lingappa J, Lambdin B, Bukusi E, Ngure K, Kavuma L, William K. Regional differences in prevalence of HIV-1 discordance in Africa and enrolment of HIV-1 discordant couples into an HIV-1 prevention trial. PLos One 2008;3:e1141.

3. Sagay AS, Onakewhor J, Galadanci $H$, Emuyevan EE. HIV status of HIV positive pregnant women in different regions of Nigeria: matters arising. African Journal of Medical Science.2006, 35 Suppl:125-9.

4. Akani CI, Erhabor O, Opurum H, Ejele A, Nwauche CA. HIV- Serodiscordance among Nigerian couples: challenges and controversies. Nigerian Medical Practitioner.2005; 48:62-6. 
5. Central Statistical Office, ORC Macro. International. Zimbabwe Demographic and Health Survey 20052006. Central Statistical Office Harare, Zimbabwe and ORC International. Calverton, MD, USA: 2007.www.measuredhs.com.p.1-454 Last accessed on 2016 Oct 13].

6. Phase III Randomized Placebo-Controlled Trial of HSV-2 suppression to prevent HIV transmission among HIV-discordant couples. Available from: http://www.depts. washington.edu/hsvhiv/. [Last accessed on 2016 Oct 3, Dec 1].

7. Kaiser R, Bunnell R, Hightower A, et al. Factors associated with HIV infection in married or cohabitating couples in Kenya: results from a nationally representative study.PLoS one 6:e17842.

8. United Nations Programme on HIV/AIDS (UNAIDS) leads. Report on the global AIDS epidemic 2013. [Online] Available@ http://www.unaids.org/en/ media/unaids/ contentassets/documents/epidemiology/2013/g r2013/unaids_global_report_2013_en.pdf. [Last accessed on 2014 May 14].

9. Rispel L, .Metcalf C, Moody C, Cloete A, Caswell G. Sexual relations and childbearing decisions of HIV-discordant couples: an exploratory study in South Africa and Tanzania. Reproductive Health Matters. 2011;19:187-93.

10. National Agency for Control of AIDS (NACA), \{Nigeria $\}$.National Strategic Plan on HIV/AIDS (2010-2015).p1-76

11. Gray RH, Wawer MJ, Brookmeyer R,, et al. Probability of HIV transmission per coital act in monogamous, heterosexual HIV discordant couples in Rakai Uganda. Lancet. 2001;357: 1149-53.

12. Bishop M, Foreit, K. Serodiscordant couples in Sub-Saharan Africa: what do survey data tell us? Washington, DC: Future Group, Health Policy Initiative, Task Order 1.Retrieved July, 27, 2010 from http://pdf.usaid.gov/pdf_docs/PNADT871.pdf.

13. Walque D. Sero-discordant couples in five African countries: implications for prevengtion strategies. Population and development review. 2007; 33:501-23.

14. Federal Ministry of Health(FMOH) $\{$ Nigeria $\}$ : HIV/STI Integrated Biological and Behavioural Surveillance Survey (IBBS) 2007:p1-75

15. Federal Ministry of Health(FMOH) $\{$ Nigeria\}:Department of Public Health National AIDS/STI Control Programme 2010 National HIV Sero-prevalence Sentinel Survey.p1-66

16. Dunukofia. Available@ http://en.wikipaedia. org/wiki/Dunukofia.[Last accessed 2013 25].

17. Kirkwood B. Essentials of medical statistics. Blackwell Scientific Publications. $2^{\text {nd }}$ Edition.2001 .p.190.

18. Araoye MO. Research methodology with statistics for health and social sciences. Nathadex Publications, saw-mill, Ilorin 2nd ed.2008: p 115-22.

19. Questionnaire modified from that of Human Sciences Research Council South Africa and Global Network of people living with AIDS. Available@www. stigmaindex. Org /.../ Summary-Booklet-on-Stigma-Index-

Survey\%20South\%20A..[Last accessed on 2014 Jan 14].

20. Statistical Package for Social Sciences (IBM SPSS) 22.0 version. Armonk NY: IBM United States. IBM Corp. 2013.

21. Ngilangwa DP, Ochako R, Mboya BA, Noronha RH, Mgomella GS Prevalence and predictors of HIV serodiscordance among cohabiting couples tested in northern Tanzania. The Pan African Medical Journal. 2015;22:275.

22. Nozaki I, Dube C, Kazuihiro K, Yamada N, James B. Social factors affecting ART adherence in rural settings in Zambia. AIDS Care. 2011; 23:831-9.

23. Tadesse M. Assessment of HIV discordance and associated risk factors among couples receiving HIV test in Dilla, Ethiopia. BMC Research Notes. 20147:893 DOI: 10.1186/1756-0500-7-893

24. Hugonnet S, Mosha F, Todd J, et al. Incidence of HIV infection in stable sexual partnerships: A retrospective cohort study of 1802 couples 
in Mwanza region, Tanzania. Journal of Acquired Immune Deficiency Syndromes.2002;30:73-80.

25. Rogers MC, Gopalakrishnan G, Kumarasamy $\mathrm{N}$, et al. HIV in couples in South India; implications for prevention. Int J STD AIDS. 2005; 16:442-5.

26. Kamali A, Carpenter LM, Whitworth JAG, Pool R, Ruberantwari A, .A seven-year trends in HIV-1 infection rates and changes in sexual behaviour, among adults in rural Uganda.AIDS.2000;14;427-34.

27. Carpenter LM, Kamali A, Ruberantwari A, Malamba S, Whitworth JAG. Rates of HIV-1 transmission within marriage in rural Uganda in relation to the HIV sero-status of the spartners. AIDS. 1997; 13:1083-9.

28. Lurie MN, Williams BG, Zuma K, et al, Who infects whom? HIV- 1 concordance and discordance among migrant and non- migrant couples in South Africa. AIDS. 2003; 17:2245-52.

29. Barden-O'Fallon JL, deGraft-Johnson J, Bisika T, Sulzbach S, Benson A, Tsui AO. Factors associated with HIV/AIDS knowledge and risk perception in rural Malawi. AIDS Behav.2004;8:131-40.

30. Gitonga M, Ballidawa J,Ndege S. Challenges and coping strategies among couples of mixed HIV status presenting at a Largs Comprehensive Care Centre in Eldoret, Kenya. Journal of Biology Agriculture and Healthcare..2012;8:18-27
31. Bennetts A, Shaffer N, Phophong P, et al. Differences in sexual behaviour between HIVinfected pregnant women and their husbands in Bangkok, Thailand. AIDS Care. 1999;11:649-61.

32. Skurnick JH, Kennedy CA, Perez G, et al. Behavioral and demographic risk factors for transmission of human immunodeficiency virus type 1 in heterosexual couples: Report from the Heterosexual HIV Transmission Study. Clin Infect Dis 1998;26:855-64.

33. Isiugo-Abanihe UC. Sociocultural aspects of HIV/AIDS infection in Nigeria. Afr $\mathrm{J} \mathrm{Med}$ Med Sci.2006;35 (Suppl.): S45-S55.

34. Duan S, Ding Y, Yang Y, et al, Prevalence and correlates of HIV discordance and concordance among Chinese-Burmese mixed couples in the Dehong prefecture of Yunnan province, China. Sex Health 2012;9:481-7.

35. Matovu JK Preventing HIV transmission in married and cohabiting HIV-discordant couples in sub-Saharan Africa through combination prevention. Curr HIV Res 2010;8:430-40.

36. Muñoz-Laboy MA, Murray L, Wittlin N, Garcia J, Terto Jr V, Parker RG. Beyond faithbased organizations: using comparative institutional ethnography to understand religious responses to HIV and AIDS in Brazil. Am J Public Health. 2011;101:972-8. 